\title{
ADSORPTION OF LEAD AND NICKEL IONS FROM AQUEOUS SOLUTION WITH CARBONS AEROGELS PREPARED FROM RESORCINOL/ FORMALDEHYDE AND PYROGALLOL/FORMALDEHYDE
}

\author{
J.L. Álvarez ${ }^{1}$, M.J. Bastidas ${ }^{1,2}$, L. Giraldo ${ }^{3}$, P. Rodríguez-Estupiñán ${ }^{4}$, \\ and J.C. Moreno-Piraján ${ }^{4 *}$ \\ ${ }^{1}$ Department of Agroindustrial Sciences, Universidad Popular del Cesar, vía a Hurtado, \\ Valledupar Colombia \\ ${ }^{2}$ Faculty of Engineering, Universidad de La Guajira, km 5 via Maicao, Riohacha, Colombia \\ ${ }^{3}$ Department of Chemistry, Faculty of Sciences, Universidad Nacional de Colombia. Cra 30 45- \\ 03, Bogotá Colombia \\ ${ }^{4}$ Faculty of Science, Department of Chemistry, Group of Porous Solids and Calorimetry, \\ Universidad de Los Andes, Carrera $1 \mathrm{~N}^{\mathrm{o}} 18^{\mathrm{a}}$-10, Bogotá, Colombia \\ *E-mail : jumoreno@uniandes.edu.co
}

\begin{abstract}
Carbon aerogels were prepared from Resorcinol/Formaldehyde (R/F) and Pyrogallol/Formaldehyde (P/F), dissolved in water, using sodium carbonate as a catalyst, water is interchanged with acetone and this with $\mathrm{CO}_{2}$ at $900{ }^{\circ} \mathrm{C}$. The aerogels are activated with $\mathrm{CO}_{2}$. Aerogels were characterized by nitrogen adsorption of $\left(\mathrm{N}_{2}\right)$ at $-196{ }^{\circ} \mathrm{C}$, thermogravimetric analysis (TGA), scanning electron microscopy (SEM) and Acid-base titration. The $\mathrm{Pb}$ (II) and Ni (II) adsorption were evaluated by isotherms from a simple solution. The solids obtained through $\mathrm{R} / \mathrm{F}$ reaction have a structure with a high surface, up to $1064 \mathrm{~m}^{2} / \mathrm{g}$, pore volume up to $0.582 \mathrm{~cm}^{3} / \mathrm{g}$ and a surface chemical composition influenced by the obtaining method, the nature of the precursors, the catalyst and the activation atmosphere, while those of $\mathrm{P} / \mathrm{F}$ show surface areas of $103.6 \mathrm{~m}^{2} / \mathrm{g}$ maximum. The thermally-treated aerogels showed better properties and in all cases, selectivity towards the lead.
\end{abstract}

Keywords: adsorption, aerogels, catalyst, porosity, supercritical dry.

(C) RASĀYAN. All rights reserved

\section{INTRODUCTION}

Some organic and inorganic substances can be released into the bodies of water as a result of domestic, agricultural and industrial activities. This leads to environmental contamination given their content of toxic substances, in relatively low concentrations, and bioaccumulative properties of some pollutants like heavy metals, which can affect the ecosystems and endangering public health ${ }^{1,2}$.

In order to minimize these effects some alternatives have been developed in order to allow the use of clean technologies and the recovery and reuse of solid waste. Regarding the handling of liquid effluents, different techniques have been used to purify them. The adsorption process on porous solids such as activated carbon is a technique that can be considered as a useful alternative for wastewater treatment ${ }^{3,4}$. The development of new solids has allowed the efficient removal of contaminants in air and aqueous phase. In this document it is analyzed the adsorption of lead and nickel ions on carbon aerogels, the preparation techniques of these materials determine their adsorbing properties.

Carbon gels have been studied for more than three decades due to their potential, since there are a wide variety of gels, depending on the precursors used and the method of preparation. The carbon gels are obtained from the polycondensation of hydroxylated benzenes (phenol, catechol, resorcinol, hydroquinone, etc.) and aldehydes (formaldehyde, furfural, etc.) in a solvent, followed by a drying step 
and subsequent carbonization ${ }^{5}$. In 1989 Pekala ${ }^{6}$, synthesized the first organic gel obtained from the polycondensation of resorcinol and formaldehyde. Since then, this organic gel has been studied, and nowadays variants are still being produced in the preparation process through which carbon gels with particular properties are achieved ${ }^{7}$.

The development of new porous solids such as carbon aerogels is of great interest since specific characteristics for the adsorption process can be obtained from the synthesis conditions. The selectivity of different ions before a particular type of adsorbing solid occurs due to the size of the pores of the material and the surface chemical composition, resulting in a specific selectivity ${ }^{4,8}$. The pore volume, the surface area and the distribution and size of the pore, can be determined by the technique of gas adsorption ${ }^{9,10}$.

This paper studies the removal of metal ions of lead and nickel from aqueous solution by using Resorcinol/Formaldehyde and Pyrogallol/Formaldehyde organic aerogels. The materials are characterized by texture and chemically by adsorption of Nitrogen $\left(\mathrm{N}_{2}\right)$ at $-196{ }^{\circ} \mathrm{C}$, thermogravimetric analysis (TGA), scanning Electron Microscopy (SEM) and acid-base titration.

The ions metal adsorption was evaluated through the determination of isotherms which allow verifying that these solids have adequate properties for the adsorption from an aqueous solution with simulated contamination of metal ions proposed. Subsequently, the adsorption of the metal ions on aerogels was fitted by applying Langmuir and Redlich-Peterson models.

\section{EXPERIMENTAL}

The preparation of organic aerogels is performed by mixing resorcinol and formaldehyde ( $\mathrm{Ratio} R / \mathrm{F}=0.5$ ) through the use of sodium carbonate as a catalyst at two different ratios $(\mathrm{R} / \mathrm{C}=50$ and 1500) in an aqueous solution according to the method described by Pekala ${ }^{6}$; the experimental conditions used are summarized in Table-1. The mixtures are agitated along a determined period of time and poured into cylindrical glass lid molds, they undergo a program of temperature, to achieve gelation and curing $\left(24 \mathrm{~h}\right.$ at $30^{\circ} \mathrm{C}$, followed by 24 hours at $50{ }^{\circ} \mathrm{C}$ and finally at $90^{\circ} \mathrm{C}$ for 48 hours). The drying with supercritical $\mathrm{CO}_{2}$ is accomplished at $31^{\circ} \mathrm{C}$ and 74 bars.

Table-1: Synthesis conditions for obtaining carbon aerogels. $(\mathrm{R}=$ Resorcinol, $\mathrm{F}=$ Formaldehyde, $\mathrm{C}=$ Catalyst $\mathrm{Na}_{2} \mathrm{CO}_{3}$ )

\begin{tabular}{c|c}
\hline System & $\begin{array}{c}\text { Resorcinol/Formaldehyde }(\mathrm{R} / \mathrm{F})=0,5 \text { or Pyrogallol/Formaldehyde } \\
(\mathrm{P} / \mathrm{F})=0,5 \mathrm{Na}_{2} \mathrm{CO}_{3}(\mathrm{R} / \mathrm{C}=50 \text { y } \mathrm{R} / \mathrm{C}=1500)\end{array}$ \\
\hline Catalyst & $\mathrm{Na}_{2} \mathrm{CO}_{3}(\mathrm{R} / \mathrm{C}=50$ y $\mathrm{R} / \mathrm{C}=1500)$ \\
\hline Solvent & Water \\
\hline Drying & Supercritical conditions $\left(41^{\circ} \mathrm{C}, 120 \mathrm{bar}\right)$ \\
\hline $\mathrm{Carbonization}_{2}$ Activation & $\mathrm{N}_{2}$ atmosphere, flow $100 \mathrm{~mL} / \mathrm{min}, 900{ }^{\circ} \mathrm{C}, 180 \mathrm{~min}$ \\
\hline $\mathrm{CO}_{2}$.
\end{tabular}

Carbon aerogel was prepared via pyrolysis of the different organic aerogels at $900{ }^{\circ} \mathrm{C}$ under $\mathrm{N}_{2}$ atmosphere $(100 \mathrm{ml} / \mathrm{min})$ using the ramp cycle as: $25-250{ }^{\circ} \mathrm{C}\left(3{ }^{\circ} \mathrm{C} / \mathrm{min}\right)$, held at $250 \mathrm{C}$ for $30 \mathrm{~min}, 250$ $600\left(1.2^{\circ} \mathrm{C} / \mathrm{min}\right.$, and held at $600 \mathrm{C}$ for $30 \mathrm{~min}$, and $600-900{ }^{\circ} \mathrm{C}\left(2^{\circ} \mathrm{C} / \mathrm{min}\right)$ and kept at $900^{\circ} \mathrm{C}$ for 180 min.

In the $\mathrm{CO}_{2}$ activation process, the carbon areogels were heated in tubular furnace as carbonization from the room temperature to $900^{\circ} \mathrm{C}$ in $3 \mathrm{~h}$ with $\mathrm{N}_{2}$ flow rate of $100 \mathrm{ml} / \mathrm{min}$, and retained at the temperature for $120 \mathrm{~min}$ under $\mathrm{CO} 2$ flow of $100 \mathrm{ml} / \mathrm{min}$, then cooled down to the room temperature under $\mathrm{N}_{2}$ flow of 100 $\mathrm{ml} / \mathrm{min}$.

The samples are known according to the following nomenclature: Ae= starting organic Aerogel; $\mathrm{CAe}=$ Carbonized Aerogel; $\mathrm{AcAe}=$ Activated Aerogel; RF=Resorcinol-Formaldehyde; PF=PyrogallolFormaldehyde

The thermogravimetric analysis (TGA) was applied to the organic gels in order to determine the carbonization conditions. Subsequently, the gels are carbonized in a tubular oven in a nitrogen atmosphere with a flow of $100 \mathrm{~mL} / \mathrm{min}$, at a heating rate of $2{ }^{\circ} \mathrm{C} / \mathrm{min}$ up to $900{ }^{\circ} \mathrm{C}$ for 3 hours. Once the 
carbonization occurs, it is activated in a tubular oven in a dioxide carbon atmosphere with a flow of $100 \mathrm{~mL} / \mathrm{min}$, at a heating speed of $2{ }^{\circ} \mathrm{C} / \mathrm{min}$ up to $900^{\circ} \mathrm{C}$ for 3 hours ${ }^{11,12}$. Another sample of the precursor will be obtained by substituting formaldehyde with pyrogallol.

The textural parameters (surface area and pore volume) of solids are estimated by physisorption of nitrogen at $-196{ }^{\circ} \mathrm{C}$ in automatic equipment IQ Quantachrome. The apparent surface areas and the micropore volume were determined by the BET equation and the Dubinin - Astakhov (AD) equation respectively ${ }^{1}$. The SEM micrographs were obtained in a JEOL microscope Model 6490-LV. The subsequent procedure entailed laying small fragments of the sample on the metal surface to achieve maximum contrast on the micrograph. The sample was then moved to the SEM camera and observed at an acceleration voltage of $5 \mathrm{KV}$ at different magnifications (between 100 and $10.000 \mathrm{X}$ ) ${ }^{13}$.

The proximate analysis for the estimation of moisture, ash and volatile material of samples is conducted under the stipulated ASTM standards. The content of fixed carbon is determined by the discrepancy respecting the rest of the tests ${ }^{14}$.

With the aim of estimating the total acidity and basicity of the surface of the carbon aerogels, solids are submerged into $\mathrm{HCl}$ and $\mathrm{NaOH} 0.1 \mathrm{M}$ previously standardized solutions. In the methodology proposed, approximately $100 \mathrm{mg}$ of the solid is submerged in $25 \mathrm{~mL}$ of the solution, in $50 \mathrm{~mL}$ plastic containers; at $25^{\circ} \mathrm{C}$ and in constant agitation for 48 hours; occasionally bubbling $\mathrm{N}_{2}$ in the solutions in order to remove environmental $\mathrm{CO}_{2}$. Finally, aliquots of $10.0 \mathrm{~mL}$ of the solutions with acid or base are titrated ${ }^{15,16}$.

The solutions of ions $\mathrm{Ni}$ (II) and $\mathrm{Pb}$ (II) are prepared with Merck®'s analytical grade reagents. For lead, they are prepared from $\mathrm{PbNO}_{3}$, for a nickel they are prepared with $\mathrm{NiCl}_{2} \cdot 6 \mathrm{H}_{2} \mathrm{O}$ using double-distilled water. The range of concentrations employed for the study of the ions is from 20 to $100 \mathrm{mg} / \mathrm{L}$. The examination of the calibration curves and solutions of the isotherms was conducted in an atomicabsorption spectrophotometer "Perkin Elmer, ANALYST 300". Five solutions of known concentration were prepared (20 to $100 \mathrm{mg} / \mathrm{L}$ ). $50 \mathrm{~mL}$ of the solutions of $\mathrm{Ni}$ (II) and $\mathrm{Pb}$ (II) was placed in a $100 \mathrm{~mL}$ flask. Then, $0,500 \mathrm{~g}$ of the solid was added to the solution with constant agitation and constant temperature at $25{ }^{\circ} \mathrm{C}$. The mixtures were left for 100 hours until the equilibrium was reached. The solution was filtered to remove the solid and to determine the equilibrium concentration ${ }^{17}$.

\section{Physicochemical characterization}

\section{RESULTS AND DISCUSSION}

The $\mathrm{N}_{2}$ adsorption isotherms at $-196{ }^{\circ} \mathrm{C}$ for the starting aerogels and their modifications are shown in Fig.-1(a) to (c) and Table-2 presents the results for the textural characterization obtained from the experimental data of $\mathrm{N}_{2}$ adsorption.

As observed in Fig.-1 to 3, the starting organic aerogels (Ae) do not exhibit high textural parameters, with apparent surface areas between 2 and $10 \mathrm{~m}^{2} / \mathrm{g}$, whose low values are not within the sensitivity range of the equipment, therefore it would be assumed that organic gels do not have an intrinsic porosity or it is blocked.

In contrast, the CAe samples, in which organic gels have undergone a carbonization process up to $900{ }^{\circ} \mathrm{C}$ with a heating speed of $2^{\circ} \mathrm{C} / \mathrm{min}$, exhibit adsorption isotherms type $\mathrm{I}$, where there is a knee at low relative pressures characteristic of microporous materials in accordance with the values of pore volumes obtained by applying the Dubinin-Astakhov model ${ }^{1}$.

When examining the results, it is observed that CAeRF50 samples show an increase in the surface area and the microporosity since this resorcinol/catalyst relation generates a more stable structure that remains after thermal treatment ${ }^{18}$.

The activated samples (AcAe) showed an increase in surface area with respect to the carbonized ones, the increase was between $40.7 \%$ and $500 \%$ (see Table-2); with respect to the carbonized sample (CAe). Taking into account that this type of treatments promotes the selective decomposition of oxygenated surface functional groups in $\mathrm{CO}$ and $\mathrm{CO}_{2}$ according to the thermal stability of each group ${ }^{8}$, this result confirms the degasification of the carbonized sample under the $\mathrm{CO}_{2}$ atmosphere, Table-2 shows the results of the $\mathrm{N}_{2}$ adsorption. The data presented are: Surface area (вет area) calculated by BET model, the 
micropore volume (Vo), the characteristic energy (E), the parameter (n) and the radius, these latter estimated by the Dubinin-Astakhov model.

Resorcinol and formaldehyde are the most often used monomers for the preparation of the polymeric framework; the particles obtained from this mixture do not have micropores because of their low structure rigidity, while the aggregation of these units leads to the formation of a porosity intraparticle ranging from mesopores to macropores ${ }^{19}$.

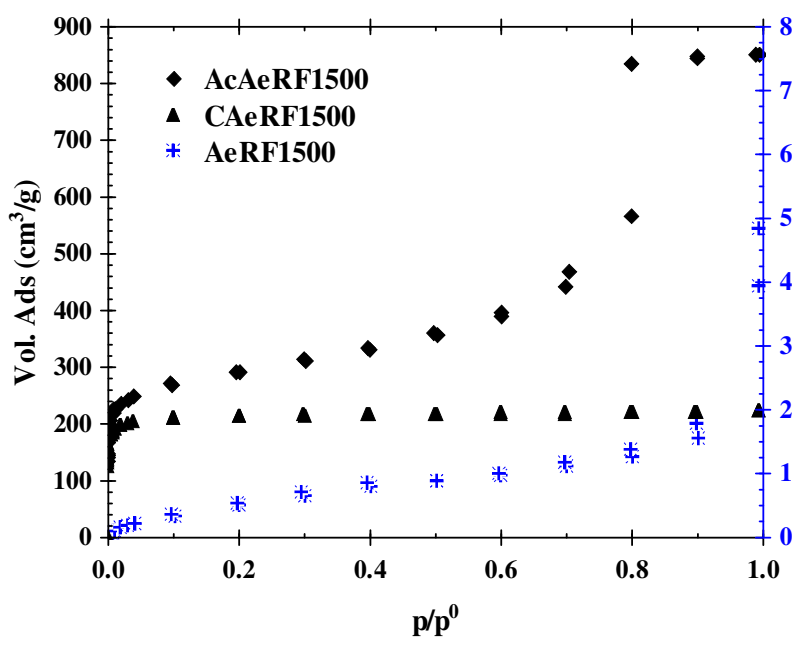

(a)

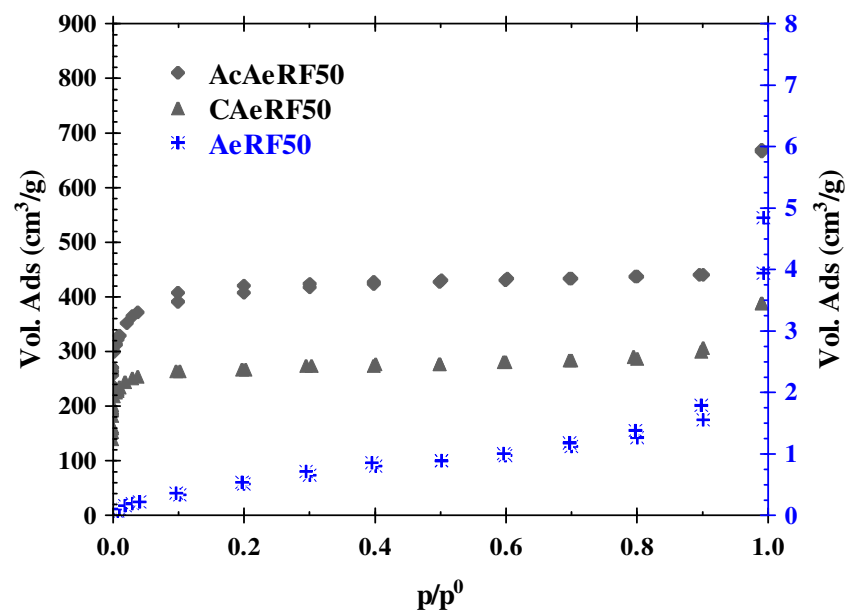

(b)

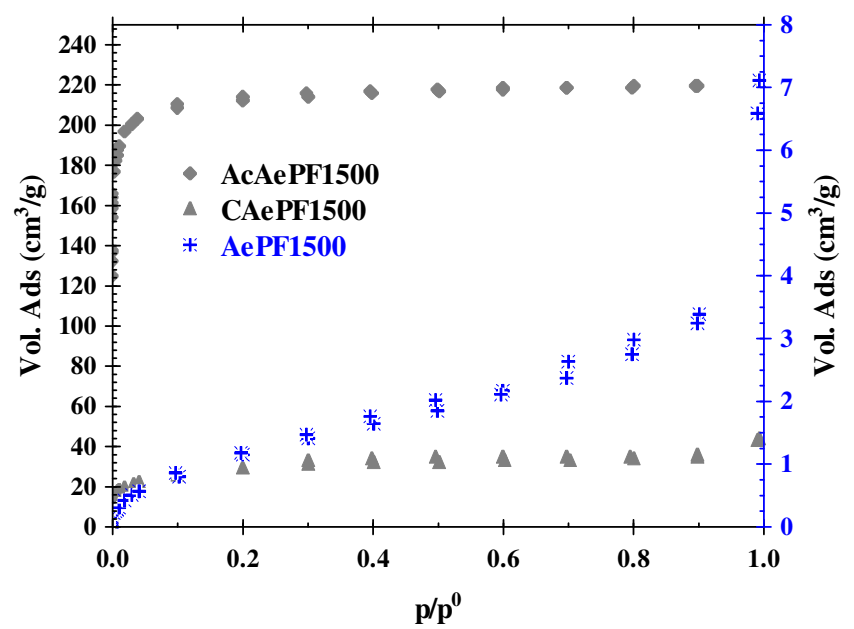

(c)

Fig. -1. Adsorption isotherms of $\mathrm{N}_{2}$ at $-196^{\circ} \mathrm{C}$ (a) series resorcinol formaldehyde $\mathrm{R} / \mathrm{C}=50$; (b) series Resorcinol Formaldehyde $\mathrm{R} / \mathrm{C}=1500$; (c) series pyrogallol formaldehyde $\mathrm{R} / \mathrm{C}=1500$

Comparing pyrogallol-formaldehyde with resorcinol-formaldehyde polymerization reaction, PF reacts more quickly; it can be associated to the structure of pyrogallol (See Fig.-2), it has three adjacent hydroxyl groups, leaving three free sites on the ring. Reactivity considerations show that the hydroxyl groups enhance the reactivity of fourth and sixth position; this could eventually allow the formation of a tridimensional network during the polymerization reaction. Despite this, during the supercritical dying, some porous structures collapse, because of the low rigidity of the polymeric framework, while the porosity intraparticle are retained after drying ${ }^{20}$. 
Table-2. Textural parameters of organic and carbon aerogels

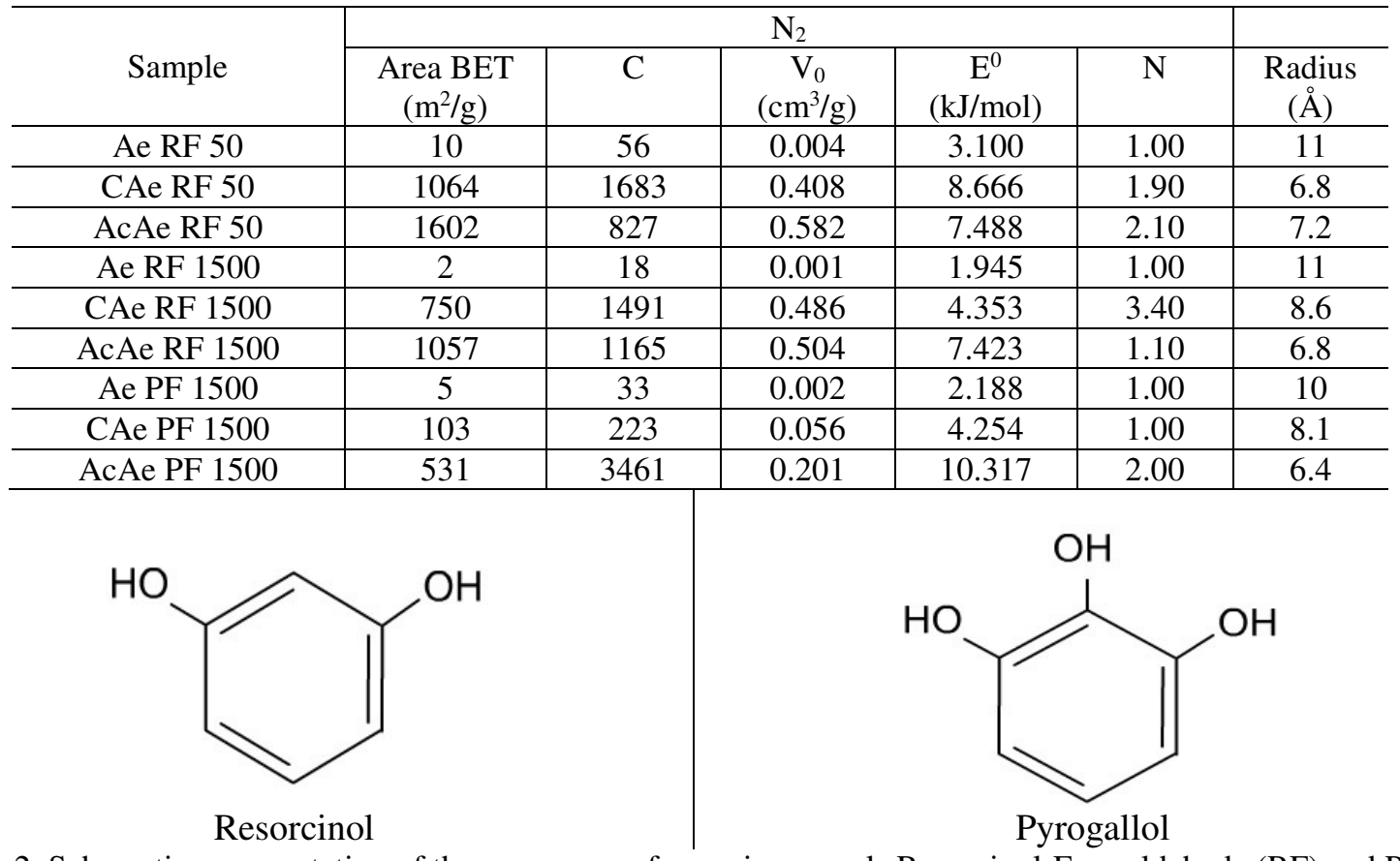

Fig. -2. Schematic representation of the precursors of organic aerogels Resorcinol-Formaldehyde (RF) and PyrogallolFormaldehyde (PF)

Figure-3 shows the images obtained by scanning electron microscopy (SEM) of the obtained aerogels' surface, where it is observable that at a micrometric scale, the morphology of the outer surface reveals agglomerations corresponding to the organization of polymeric particles of the precursors. Some cavities and roughness are also observed. These spaces are around $1 \mu \mathrm{m}{ }^{10}$.
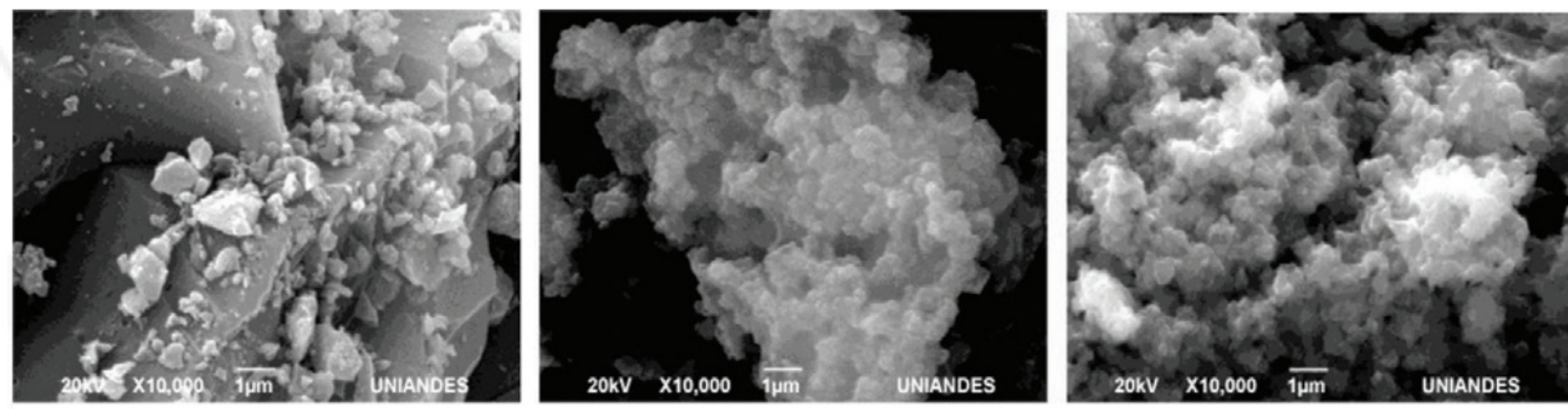

Fig.- 3: SEM images at different magnification

Despite micropores and mesopores are not visible; the photographs reveal shapes and localization of the macropores over the sample's surface. Macropores are formed during the activation under the effect of the oxidation gas, in this case, $\mathrm{CO}_{2}$ and the loss of volatile material during pyrolysis; this favors the diffusion processes ${ }^{21}$.

Table-3 summarized the data obtained from the proximate analysis in each sample. The moisture percentage oscillates between 9,10 and $26,1 \%$, and the volatile material varies between 13,8 and $57,7 \%$, being, in both cases, greater in organic aerogels, which is related to the wider surface chemistry of the organic gels and their precursors that promote the interaction with water molecules o the environment. Additionally, organic gels despite their polymeric structure exhibit a lower thermal stability than the carbonized and activated samples. At the same time, the fixed carbon is greater in the carbonized and 
activated solid samples, and decreases in the organic samples where the volatile material increases. Finally, in regards to the content of ash in the samples, it is found that this parameter remains uniform and must be originated by the use of the catalyst, in this case, the sodium carbonate.

Table-3: Proximate analysis of the carbon aerogels samples

\begin{tabular}{c|c|c|c|c}
\hline \multicolumn{5}{c}{ Tample-3: Proximate analysis of the carbon aerogels samples } \\
\cline { 2 - 5 } & \% Moisture & \% Volatile Material & \% Ash & \% Fixed Carbon \\
\hline Ae RF 50 & 25.5 & 40.6 & 1.92 & 32.6 \\
\hline CAe RF 50 & 13.2 & 16.2 & 1.95 & 68.4 \\
\hline AcAe RF 50 & 16.7 & 13.8 & 1.91 & 68.3 \\
\hline Ae RF 1500 & 26.1 & 24.2 & 1.01 & 28.5 \\
\hline CAe RF 1500 & 9.10 & 20.1 & 1.12 & 69.4 \\
\hline AcAe RF 1500 & 12.7 & 18.1 & 1.01 & 70.9 \\
\hline Ae PF 1500 & 22.9 & 57.7 & 1.21 & 18.9 \\
\hline CAe PF 1500 & 15.4 & 21.8 & 1.23 & 62.3 \\
\hline AcAe PF 1500 & 9.38 & 22.9 & 1.19 & 75.1 \\
\hline
\end{tabular}

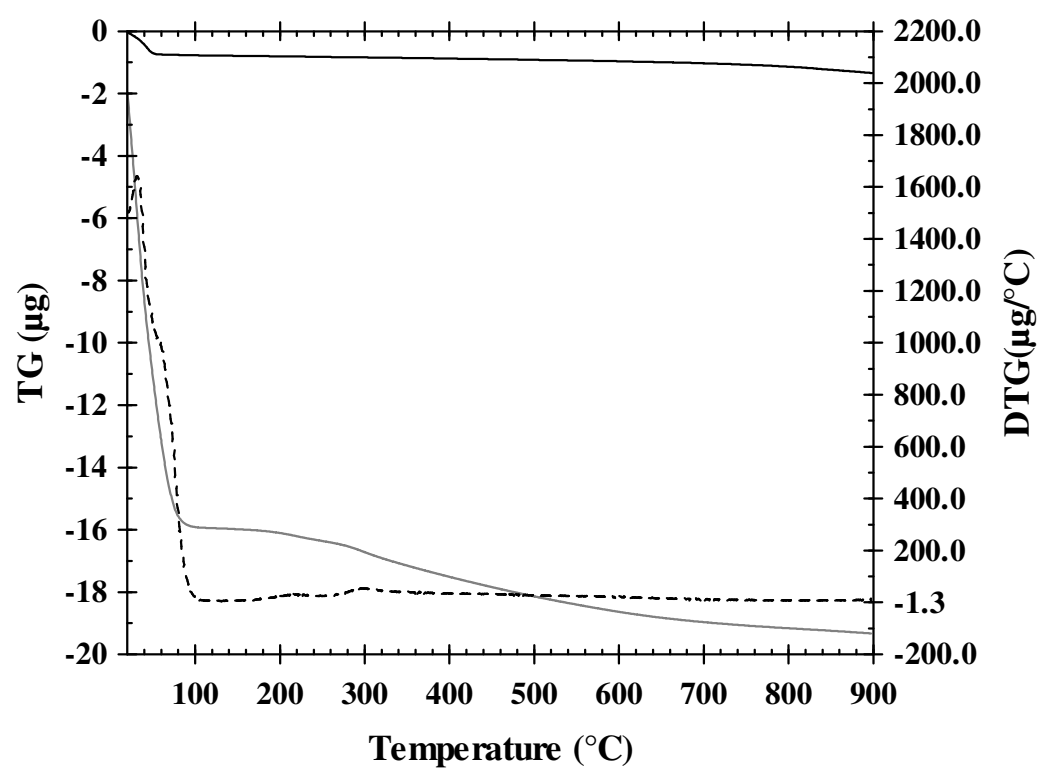

Fig. -4. TG y DTG of the organic aerogel of pyrogallol and formaldehyde $\mathrm{R} / \mathrm{C}=1500$ and TG CAe PF

The thermogravimetric analysis (see Fig.-4) performed in organic gels shows that there are two differentiating stages during the thermal treatment ${ }^{22}$. In a first stage, up to $120^{\circ} \mathrm{C}$, water and/or acetone, solvents employed during the gel synthesis, desorption takes place as well as residues resulting from the organic precursors utilized. In the second stage, between $200{ }^{\circ} \mathrm{C}$ to $600{ }^{\circ} \mathrm{C}$, during the process of carbonization of the organic gel at low temperatures, the breakage of $\mathrm{C}-\mathrm{O}$ bonds occurs and at higher temperatures, $\mathrm{C}-\mathrm{H}$ bonds take place ${ }^{23}$.

Table- 4 shows the results obtained by the acid-base titrations. Based on the results obtained, the changes produced in the surface chemistry of each sample are evaluated according to the treatment to which it was subjected.

Table-4: Acid and basic superficial groups determined by Boehm titration

\begin{tabular}{c|c|c}
\hline Sample & $\begin{array}{c}\text { Acidity } \\
\text { Total } \mu \mathrm{mol} / \mathrm{g}\end{array}$ & $\begin{array}{c}\text { Basicity } \\
\text { Total } \mu \mathrm{mol} / \mathrm{g}\end{array}$ \\
\hline Ae RF 50 & 0.141 & 0.065 \\
\hline CAe RF 50 & 0.032 & 0.191 \\
\hline
\end{tabular}




\begin{tabular}{c|c|c}
\hline AcAe RF 50 & 0.121 & 0.102 \\
\hline Ae RF 1500 & 0.132 & 0.089 \\
\hline CAe RF 1500 & 0.048 & 0.095 \\
\hline AcAe RF 1500 & 0.109 & 0.072 \\
\hline Ae PF 1500 & 0.211 & 0.073 \\
\hline CAe PF 1500 & 0.106 & 0.107 \\
\hline AcAe PF 1500 & 0.089 & 0.112 \\
\hline
\end{tabular}

It is observed that samples corresponding to precursor organic gels have a greater amount of acid-type superficial groups in relation to the carbonized and the activated samples. The evaluated groups come from the hydroxymethyl, methylene and ether-type radicals that originate the polymer, said groups, by the thermal treatment at $900{ }^{\circ} \mathrm{C}$, decrease drastically ${ }^{24}$. It is considered that the carboxylic groups decompose between 250 and $400^{\circ} \mathrm{C}$, lactones between 400 and $650^{\circ} \mathrm{C}$ and phenols between 600 and $800^{\circ} \mathrm{C}$, and at higher temperatures over $1000^{\circ} \mathrm{C}$, quinones and pyrones groups decompose ${ }^{8}$. According to this it can be seen that the heat treatment effectively decreases the concentration of these groups on the surface.

As for the basicity parameter of the surface, it is attributed to chromene and pyrone groups that can be formed in thermal treatments at high temperatures, but additionally this basic character is product of the electronic density given by the delocalized $\pi$ electrons ${ }^{8}$.

\section{$\mathrm{Pb}$ (II) and Ni (II) adsorption from aqueous solution: Experimental Data and theoretical models}
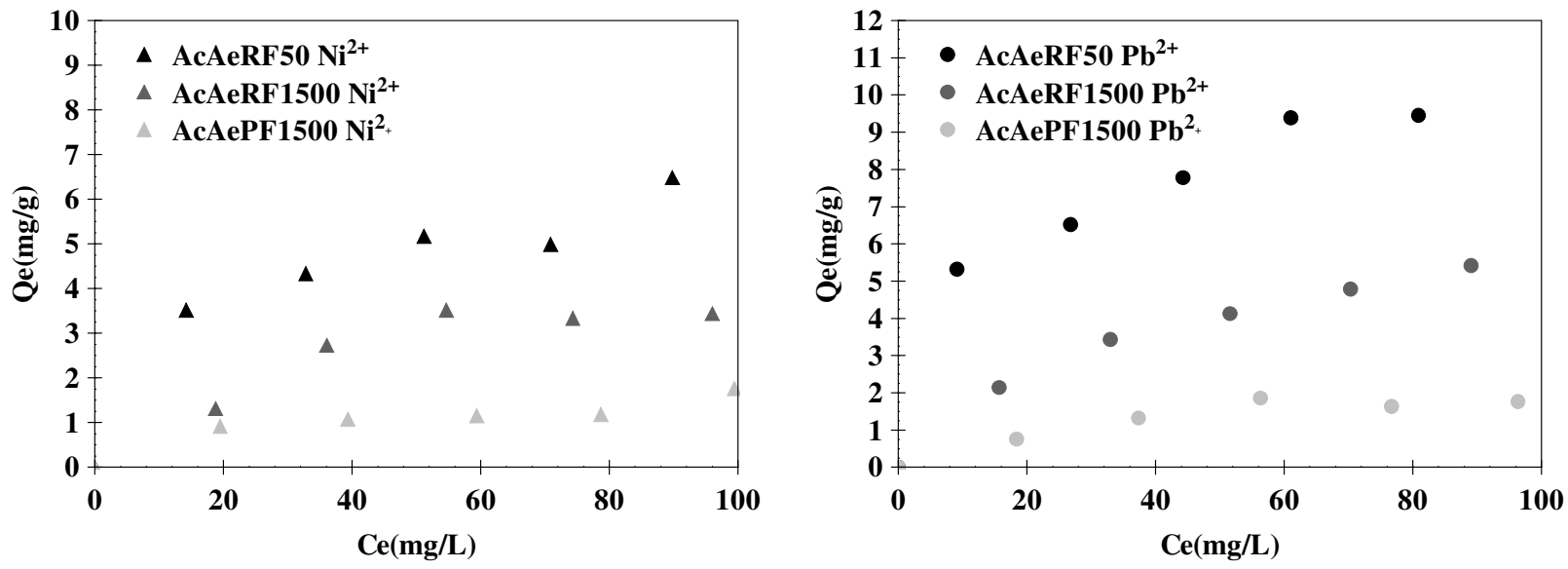

Fig. -5: Isotherms of nickel ( $\mathbf{\Delta})$ and lead (•) solutions in the samples AcAeRF50, AcAeRF1500, AcAePF1500

The importance of oxygenated groups on the surface and the surface area of aerogels in the adsorption of ions from aqueous solution has been highlighted by many authors $1,4,8,9,17,25$. In general, it is considered that the removal of an ion is attributed mainly to the interaction of said groups and the ion through different mechanisms that involve specific interactions, although diffusional processes should also be favored with a suitable porous structure.

Next, the solids of higher textural parameters (AcAeRF50, AcAeRF1500 and AcAePF1500) are evaluated in the adsorption of $\mathrm{Pb}$ (II) and $\mathrm{Ni}$ (II) ions and the effects of their properties on the adsorption capacity of the different samples (See Fig. -5). Metal ion sorption on aerogels, which come from polyphenolic precursors (resorcinol and pyrogallol) is assumed that the ion removal occur through different mechanisms including: (i) formation of complexes of coordination between oxygen groups and cations; (ii) electrostatic attraction with $\pi$ sites and valence orbitals of metal transition ions and (iii) ion exchange with protonated hydroxyl groups through proton exchange ${ }^{25-30}$.

In addition, the simple adsorption experiments were adjusted to different theoretical models, in Tables 5 and 6 there is a summary of the resulting parameters of applying Langmuir, Freundlich, Redlich-Peterson 
RASĀYAN J. Chem.

Vol. 11 | No. 2 |780 - 790 | April - June | 2018

and Toth models to the experimental data of adsorption. The patterns' adjustment parameters are calculated by the least squares method, employing Rosenbrock and quasi-Newton optimization algorithm.

Table-5: Summary of the adjustment of two parameters models for the adsorption systems of $\mathrm{Ni}$ (II) y $\mathrm{Pb}$ (II)

\begin{tabular}{c|c|c|c|c|c|c}
\hline \multirow{2}{*}{ Sample } & \multicolumn{3}{|c|}{ Langmuir model } & \multicolumn{3}{c}{ Freundlich model } \\
\cline { 2 - 7 } & Qo & $\mathrm{K}_{\mathrm{L}}$ & $\mathrm{R}^{2}$ & $\mathrm{~K}_{\mathrm{F}}$ & $\mathrm{n}$ & $\mathrm{R}^{2}$ \\
\hline AcAe RF 50-Ni & 10.7 & 0.085 & 0.999 & 0.515 & 0.82 & 0.937 \\
\hline AcAe RF 1500-Ni & 3.25 & 0.021 & 0.992 & 0.355 & 0.78 & 0.857 \\
\hline AcAe RF 1500-Ni & 1.62 & 0.008 & 0.989 & 0.278 & 2.12 & 0.959 \\
\hline \multirow{2}{*}{ Sample } & \multicolumn{2}{|c|}{ Langmuir model } & \multicolumn{3}{|c}{ Freundlich model } \\
\cline { 2 - 7 } & Qo & $\mathrm{K}_{\mathrm{L}}$ & $\mathrm{R}^{2}$ & $\mathrm{~K}_{\mathrm{F}}$ & $\mathrm{n}$ & $\mathrm{R}^{2}$ \\
\hline AcAe RF 50-Pb & 12.6 & 0.105 & 0.999 & 1.50 & 0.80 & 0.956 \\
\hline AcAe PF 1500-Pb & 6.28 & 0.055 & 0.996 & 0.851 & 0.96 & 0.862 \\
\hline AcAe PF 1500-Pb & 3.52 & 0.009 & 0.982 & 0.591 & 3.00 & 0.978 \\
\hline
\end{tabular}

Langmuir's model seems to be more adjustable to the experimental data. Besides, the maximum adsorption capacity, represented in the Qo model, is useful to compare the potential of adsorption capacity in each sample. In the tests developed, there is more adsorption capacity of $\mathrm{Ni}$ (II) in the sample AcAe RF 50 with $10.7 \mathrm{mg} / \mathrm{g}$ which decreases at $3,25 \mathrm{mg} / \mathrm{g}$ for AcAe RF 1500 y $1,52 \mathrm{mg} / \mathrm{g}$ samples for AcAe PF 1500 . This behavior is related to the smallest amount of superficial groups produced in the treatment of activation. It is also observed that it exhibits a greater capacity of removing $\mathrm{Pb}$ (II), but the decrease in the maximum capacity of adsorption of the other samples is not as dramatic as in the previous case. This outcome allows concluding that acid groups and the surface area developed in sample AcAe RF 50 favor the adsorption of ions in aqueous solution and additionally, this sample shows a greater basicity which increases with thermal treatment.

Table-6: Summary of adjustment of three parameters models for the adsorption systems of lead and nickel

\begin{tabular}{c|c|c|c|c|c|c|c|c}
\hline \multirow{2}{*}{ Sample } & \multicolumn{4}{|c|}{ Redlich-Peterson model } & \multicolumn{4}{c}{ Toth model } \\
\cline { 2 - 9 } & $\mathrm{K}_{\mathrm{RP}}$ & $\mathrm{a}_{\mathrm{RP}}$ & $\mathrm{B}$ & $\mathrm{R}^{2}$ & $\mathrm{~K}_{\mathrm{T}}$ & $\mathrm{a}_{\mathrm{T}}$ & $\mathrm{T}$ & $\mathrm{R}^{2}$ \\
\hline AcAe RF 50-Ni & 0.0875 & 0.0180 & 0.400 & 0.915 & 10.3 & 281 & 1.13 & 0.999 \\
\hline AcAe PF 1500-Ni & 0.0158 & 0.0098 & 0.979 & 0.982 & 5.01 & 102 & 1.85 & 0.992 \\
\hline AcAe PF 1500-Ni & 0.0170 & 0.0158 & 0.889 & 0.989 & 5.70 & 58.1 & 0.904 & 0.999 \\
\hline \multirow{3}{*}{ Sample } & \multicolumn{3}{|c|}{ Redlich-Peterson model } & \multicolumn{5}{c}{ Toth model } \\
\cline { 2 - 9 } & $\mathrm{K}_{\mathrm{RP}}$ & $\mathrm{a}_{\mathrm{RP}}$ & $\mathrm{B}$ & $\mathrm{R}^{2}$ & $\mathrm{~K}_{\mathrm{T}}$ & $\mathrm{a}_{\mathrm{T}}$ & $\mathrm{T}$ & $\mathrm{R}^{2}$ \\
\hline AcAe RF 50-Pb & 0.0923 & 0.0185 & 0.856 & 0.897 & 15.9 & 185 & 1.09 & 0.994 \\
\hline AcAe PF 1500-Pb & 0.0202 & 0.0078 & 0.865 & 0.996 & 7.13 & 152 & 1.08 & 0.992 \\
\hline AcAe PF 1500-Pb & 0.411 & 0.0256 & 0.879 & 0.997 & 5.07 & 26.2 & 0.879 & 0.999 \\
\hline
\end{tabular}

The models of three adjustment parameters described the experimental data of the adsorption of ions $\mathrm{Ni}$ (II) and $\mathrm{Pb}$ (II) more extensively. Among the models employed and according to the correlation coefficient, Toth's model demonstrated greater adjustment. This model is applied to heterogeneous systems and it derives from the potential theory; besides, it assumes a quasi-Gaussian energetic distribution, that is, most places show a lower energy with respect to the maximum energy of adsorption $^{26-30}$, this is consistent considering that the surface of a carbonaceous porous solid is heterogeneous due to the chemical nature of the surface exposed to the adsorbate molecules.

Figure- 6 presents the experimental data obtained in the simple adsorption isotherms of nickel and lead on samples AcAe RF 50, AcAe RF 1500 and AcAe PF 1500 adjusted to Toth's model.

In these Figures, it is important to observe the major adsorption of $\mathrm{Pb}$ (II) and the change in shape of the isotherms in the sample, showing a shift in the process of adsorption of ions and a greater affinity to solids in all cases. 
As the amount of surface groups and the available area increase, the greater capacities of adsorption are observed and consequently the specific interactions in the adsorption process are favored, which ratifies the importance of superficial groups and the establishment of specific interactions in the process of ions adsorption.

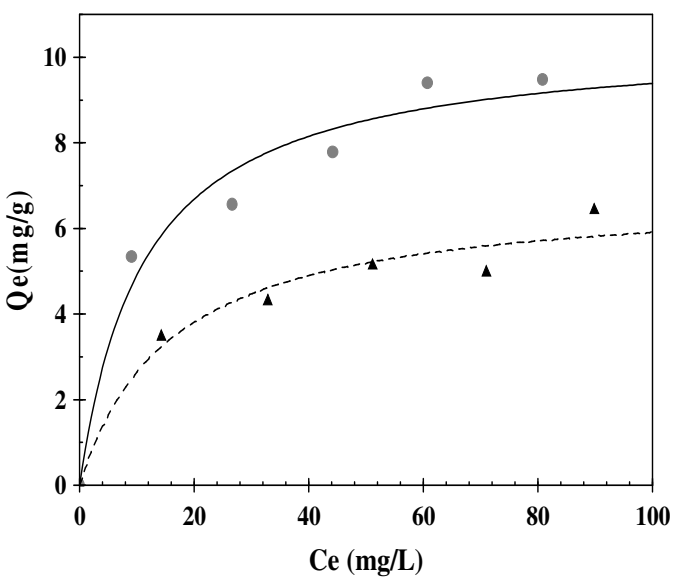

(a)

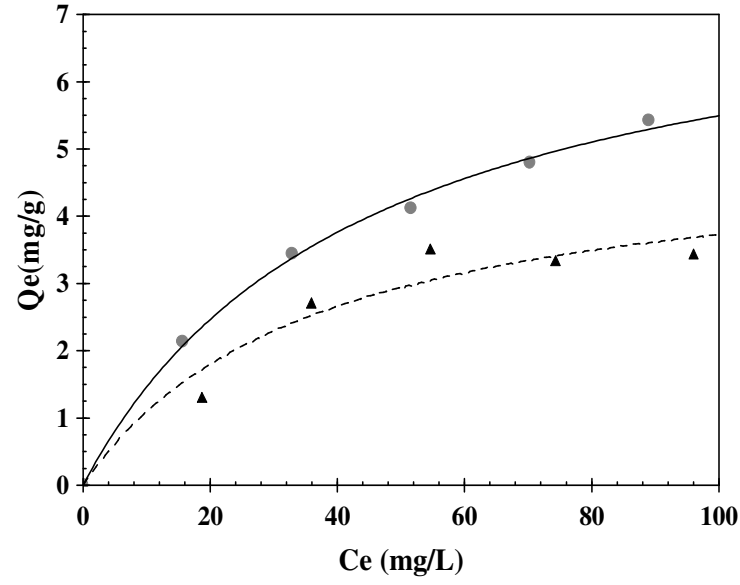

(b)

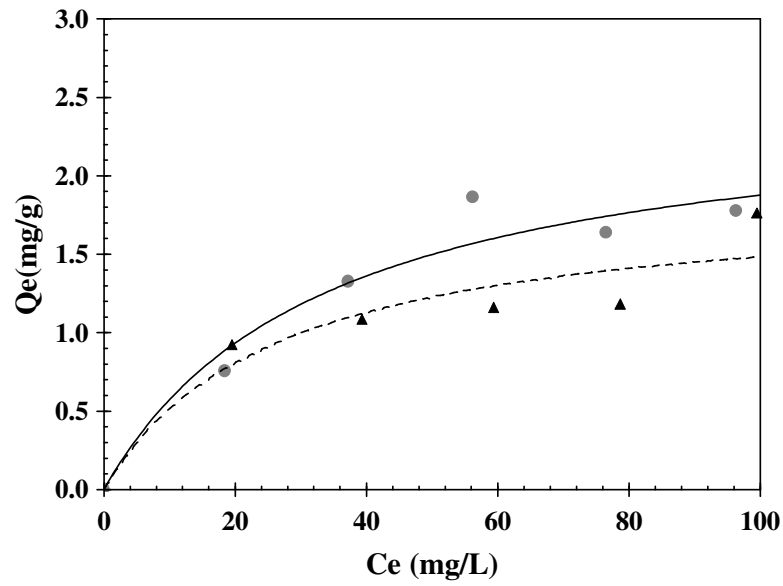

(c)

Fig. -6: Isotherms in nickel ( $\mathbf{\Delta})$ and lead (•) solutions in the samples adjusted to Toth's model on (a) AcAeRF50; (b) AcAeRF1500 ; (c) AcAePF1500

Table-7: Percentage of nickel and lead ions removal in simple adsorption

\begin{tabular}{c|c|c}
\hline Sample & $\begin{array}{c}\text { \%Removal } \\
\text { Ni(II) }\end{array}$ & $\begin{array}{c}\text { \% Removal } \\
\mathrm{Pb}(\mathrm{II})\end{array}$ \\
\hline AcAe RF 50 & 33.7 & 54.2 \\
\hline AcAe RF 1500 & 13.4 & 21.2 \\
\hline AcAe PF 1500 & 8,81 & 7,70 \\
\hline
\end{tabular}

Results show different efficiency for each solid according to the capacity for removing Ni (II) y $\mathrm{Pb}$ (II), with maximum capacities between 8.81 and $54.2 \%$. The best removal was for the solid AcAe RF 50 for $\mathrm{Ni}$ (II) y Pb (II).

\section{CONCLUSION}

Carbon aerogels depict satisfactory textural properties which allow a positive behavior in the treatment of simulated residual waters contaminated with metal ions of toxic metals such as $\mathrm{Ni}$ (II) y $\mathrm{Pb}$ (II). 
Thermal treatments modify textural and chemical properties in starting organic gels. A major stability for the porous structure of the sample ACAE RF 50 is noticed. These samples undergoing thermal treatment under carbon dioxide environment subsequent to the carbonization treatment presented an increase in the surface area.

The activation treatment promotes the formation of acid and basic groups, in contrast with the carbonization treatment under nitrogen environment.

Lastly, the solids activated in the adsorption of $\mathrm{Ni}$ (II) y $\mathrm{Pb}$ (II) ions from an aqueous solution were tested and the relations with the estimated physical-chemical parameters and the capacities of adsorption were established. From this, it can be concluded that the experimental data for the isotherms of adsorption of $\mathrm{Ni}$ (II) in solids decrease in comparison with the ones obtained by simple adsorption of $\mathrm{Pb}$ (II) ions; this demonstrates the selectivity of the solids prepared.

The functional groups perform a paramount role in the removal of metal ions, creating a synergic effect in terms of mechanisms between the adsorption and the ionic interchange. It could be established that nickel ions interact with acidic groups at a higher rate, evidenced by the drastic decrease of the adsorption capacity in the Pyrogallol samples.

\section{ACKNOWLEDGMENT}

The authors wish to thank the framework agreement established between the Universidad de la Guajira and Universidad de Los Andes (Bogotá, Colombia) for the scientific support to carry out this research. The authors also appreciate the grant for the funding of research programs for Associate Professors, Full Professors and Emeritus Professors, announced by Faculty of Sciences of the Universidad de los Andes (Colombia), 11-28-2017, 2018-2019, according to the project "Thermodynamic Characterization of the Adsorption of Contaminants on Porous Adsorbentes".

\section{REFERENCES}

1. F. Rouquerol, J. Rouquerol, K. Sing, M. Guillaume, P. Llewellyn, 2014, Introduction, in: F. Rouquerol, J. Rouquerol, K. Sing, M. Guillaume, P. Llewellyn (Eds.), Adsorption by Powders and Porous Solids Principles, Methodology and Applications. Second edition. Elsevier Ltd,. Oxford, pp.114, DOI:10.1016/B978-0-08-097035-6.00001-2

2. N.F Gray, 2010, Chapter 14: Introduction to Wastewater Treatment. in: N.F. Gray (Eds) Water Technology: An Introduction for Environmental Scientists and Engineers, Third Edition. Butterworth Heineman. New York, pp. 425-459, DOI: 10.1016/B978-1-85617-705-4.00014-9

3. R. Dores, A., Hussain, M. Katebah, S. Adham, Advances in Gas Processing., 3, 102(2012)

4. E.A. Deliyanni, G.Z. Kyzas, K.S. Triantafyllidis, K.A. Matis, Open Chem.,13, 699(2015), DOI: 10.1515/chem-2015-0087

5. Z.B. Zapata, F. Carrasco-Marín, J. Vicente, C. Moreno-Castilla, Langmuir., 29, 6166(2013), DOI: 10.1021/la4007422

6. R.W Pekala, US Patent 4997804 (1991).

7. G-P.Wu, J. Yang, D. Wang, R. Xu, K. Amine, C-X. Lu. Chung, Mater. Lett., 115, 1(2014), DOI: 10.1016/j.matlet.2013.10.003

8. J. Figueiredo, M.F.R. Pereira, Catal. Today.,150, 2(2010), DOI: 10.1016/j.cattod.2009.04.010

9. Z. Li, W. Yan, S. Dai, Langmuir., 21,11999 (2005), DOI: 10.1021/la051608ul

10. K.S.W. Sing, 2014, Assessment of Surface Area by Gas Adsorption. in Adsorption by Powders and Porous Solids Principles, Methodology and Applications. Second edition. Elsevier Ltd, Oxford, pp.237-263, DOI: 10.1016/B978-0-08-097035-6.00007-3

11. A.C. Pierre, G.M. Pajonk, Chemical Reviews., 102, 4243(2002), DOI: 10.1021/cr0101306

12. C.J. Brinker, G.W. Scherer, 1990, Chapter 10 - Surface Chemistry and Chemical Modification in: Sol-Gel Science: The Physics and Chemistry of Sol-Gel Processing, Academic Press, San Diego, pp: 616-672, DOI: 10.1016/B978-0-08-057103-4.50015-5

13. O.W. Achaw, 2012, A Study of the Porosity of Activated Carbons Using the Scanning Electron Microscope. in: V. Kazmiruk (Eds), Scanning Electron Microscopy, Intech., Rijeka, pp: 473-490, DOI: $10.5772 / 36337$ 
14. ASTM, ASTM D 3172, ASTM, Philadelphia, (2012).

15. S. Goertzen, K. Thériault, A. Oickle, A. Tarasuk, H. Andreas, Carbon., 48, 1252(2010), DOI: 10.1016/j.carbon.2009.11.050

16. Y. Kim, S. Yang, H. Lim, T. Kim, C. Park, Carbon., 50, 3315(2012), DOI: 10.1016/j.carbon.2011.12.030

17. E. Da'na, A. Sayari, Desalination., 285, 62 (2012), DOI: 10.1016/j.desal.2011.09.034

18. Z. Zapata-Benabithe, C. Moreno-Castilla, F Carrasco-Marín, J. Solgel Sci. Technol., 75, 407 (2015), DOI: $10.1007 / \mathrm{s} 10971-015-3713-5$

19. D. Wu, F. Xu, B. Sun, R. Fu, H. He, K. Matyjaszewski, Chem. Rev., 112,3959(2012), DOI: $10.1021 / \mathrm{cr} 200440 z$

20. M. Can, E. Bulut, M. Özacar. J. Chem. Eng. Data., 57(10), 2710(2012), DOI: 10.1021/je300582y

21. Y. Tao, M. Endo, K. Katsumi, Recent Pat. Chem. Eng., 1(3), 192(2008), DOI: $10.2174 / 1874478810801030192$

22. J. Wang, M-m. Chen, C. Wang, J. Zheng, Mater. Lett., 68,446(2012), DOI: 10.1016/j.matlet.2011.10.106

23. X. Wang, R. Liu, M. Waje, Z. Chen, Y. Yan, K. Bozhilov, P. Feng, Chem. Mater., 19, 2395(2007), DOI:10.1021/cm070278r

24. J. Zhu, R, Li, W. Niu, Y. Wu, X. Gou, Int. J. Hydrogen Energy., 38, 10864(2013), DOI: 10.1016/j.ijhydene.2013.01.150

25. H. Treviño-Cordero, L. Juárez-Aguilar, D. Mendoza-Castillo, V. Hernández-Montoya, A, BonillaPetriciolet, M. Montes-Morán, Ind. Crops Prod., 42, 315(2013), DOI: 10.1016/j.indcrop.2012.05.029

26. V.K. Saini, M. Andrade, M.L. Pinto, A.P. Carvalho, J, Pires, Sep. Purif. Technol., 75, 366(2010), DOI: $10.1016 /$ j.seppur.2010.09.006

27. A. Pérez-Cadenas, C. H. Ros, S. Morales-Torres, M. Pérez-Cadenas, P.J. Kooyman, C. MorenoCastilla, F. Kapteijn, Carbon., 56, 324(2013), DOI: 10.1016/j.carbon.2013.01.019

28. M. Can, Int. J. Mater. Prod. Tec., 52, 347 (2016), DOI: 10.1504/IJMPT.2016.075498

29. Z. Guo, J. Fan, , J. Zhang, Y. Kanga, H. Liu, L. Jiang, C. Zhang, J. Taiwan Inst. Chem. E., 58, 290(2016), DOI: 10.1016/j.jtice.2015.05.041

30. A. Alfarra, E. Frankowiakc, F. Béguin, Appl. Surf. Sci., 228, 84(2004), DOI: 10.1016/j.apsusc.2003.12.033

[RJC-2095/2018] 